\title{
Influence of Carbon Content on Solidifying Shell Growth of Carbon Steels at the Initial Stage of Solidification
}

\author{
Mikio Suzuki ${ }^{1, *}$ and Yuichi Yamaoka ${ }^{2}$ \\ ${ }^{1}$ Materials and Processing Research Center, NKK Corp., JFE Fukuyama 721-8510, Japan \\ ${ }^{2}$ Fukuyama Works, NKK Corp., JFE, Fukuyama 721-8510, Japan
}

\begin{abstract}
A dipping test that a water cooled copper plate was continuously dipped at $14 \mathrm{~mm} / \mathrm{s}$ was performed in order to investigate solidifying shell growth in initial solidification. Anomalous rough surfaces and uneven shell growth were exhibited for an ultra-low carbon steel (0.005 mass $\% \mathrm{C})$ and a hypo-peritectic carbon steel $(0.116$ mass $\%$ C), while for a low carbon steel $(0.044$ mass $\%$ C) and a hyper-peritectic carbon steel $(0.304$ mass \% C), flat surfaces were formed. The carbon content dependence of the anomalous uneven shell growth can be explained by stress caused by solidification shrinkage and $\delta / \gamma$ transformation occurring from a fraction solid 0.7 , where shell begins to have strength, to 1.0 , complete solidification state. Besides the analysis shows that decrease of the cooling rate can reduce the stress in the shell generated during the initial solidification.
\end{abstract}

(Received October 10, 2002; Accepted February 24, 2003)

Keywords: surface roughness, initial solidification, solidification shrinkage, $\delta / \gamma$ transformation, uneven shell growth, hypo-peritectic carbon steel, ultra-low carbon steel

\section{Introduction}

Steel shell growth in a continuous casting mold is substantially influenced by carbon content in steel. Shell deformation occurs as a consequence of shell shrinkage due to thermal contraction and $\delta / \gamma$ transformation during initial solidification. This deformation induces the surface roughness of the shell, resulting in anomalous decrease of heat transfer rate from a shell to a mold, often causing uneven shell growth and surface crack in the shell. ${ }^{1-3)}$

Matsumiya et al. $^{4)}$ have calculated stress and strain in freely shrinking shell within a continuous casting mold. They showed that the maximum tensile stress was resulted in a 0.14 mass \% carbon steel in the brittle temperature range near the melting point, and formation of the thinner shell was mathematically modeled from shell deflection caused by the thermal stress formed on cooling and the stress induced by $\delta / \gamma$ transformation.

Mizoguchi et al. ${ }^{5)}$ have analyzed quantitatively shell growth at the initial stage of solidification coupling with the shell deformation due to thermal stress and showed that the unevenness of shell growth is improved by a mild cooling in a mold.

Mizukami et ll $^{6)}$ have conducted a dipping test of copper chill with measurement of a surface temperature of solidifying shell using a two-dimensional optical pyrometer. They have found out that undercooling and recalesence phenomena appear for ultra-low carbon, low carbon and middle carbon steels and temperature fluctuation on the shell surface after the recarescence is increased in order, low carbon, ultra-low carbon and middle carbon steels. Hence, they have claimed that the deformation of an initial shell is caused by stress in the shell generated by the temperature fluctuation after the recaresence and leads to the uneven shell growth.

In contrast, Esaka et al. ${ }^{7)}$ have performed a dipping test

*Present address: Industrial Property Coorporation Center, Tokyo 1300022, Japan. using two kinds of chill blocks, a flat and a rough blocks in order to investigate the anomalous unevenness of shell growth of a hypo-peritectic carbon steel and simultaneously measured the cooling curve of the start of solidification. They have claimed that a difference of the unevenness of shell growth between the two chill blocks is caused by the nucleation rate. Furthermore, Kajitani et al. ${ }^{8)}$ have investigated the unevenness of shell growth of the ultra-low carbon steel in comparison with that of a 0.15 mass $\% \mathrm{C}$ steel with the same dipping test. They have concluded that since the nucleation rate for the ultra-low carbon steel is lower than that for the hypo-peritectic carbon steel, the unevenness of shell growth is more anomalously exhibited. However, they do not explain the reason why a mild cooling in a mold can improve the unevenness of shell growth of the hypoperitectic carbon steel.

Tomono et al. ${ }^{9)}$ have in-situ observed meniscus shape of liquid metal by carrying out a bottom pouring test and investigated various factors affecting the surface quality of the shell.

Kudoh et al. ${ }^{10)}$ have performed a steel chill block dipping test and investigated the effect of the dipping speed of the chill block on the formation of ripple mark and solidification structure of the solidified shell.

Dong et al. ${ }^{11)}$ have measured the free deformation of initial shells of $\mathrm{Fe}-\mathrm{C}$ alloys with a molten steel droplet method and showed that a very strong deformation in initial shell demonstrates at pure iron and 0.12 mass $\%$ carbon steel.

In this study, we have investigated the effect of carbon content in molten steel on the shell growth and its surface quality and found out the anomalous surface roughness and uneven shell thickness of the ultra-low carbon steel and the hypo-peritectic carbon steel. And formation mechanism of the anomalous uneven shell growth generated in the ultra-low carbon steel and the hypo-peritectic carbon steel were discussed with stress induced in a shell due to solidification shrinkage and $\delta / \gamma$ transformation occurring during solidification. 


\section{Experimental}

About a $100 \mathrm{~kg}$-steel was induction melted in the air atmosphere, the chemical composition of molten steel was adjusted and the temperature was controlled to maintain superheat to be at 30,50 and $90 \mathrm{~K}$ within $\pm 10 \mathrm{~K}$. Removing scum floating on the surface of molten steel, a water cooled copper plate, that faces of the copper plate except one face were coated by alumina castable as shown in Fig. 1, was dipped continuously at a speed of $14 \mathrm{~mm} / \mathrm{s}$. The copper plate was dipped into approximately $250 \mathrm{~mm}$ in depth from the molten steel level and subsequently pulled out. The molten steel crystallized and the shell was formed on the copper plate. Transverse surface depressions, which are called ripple mark, were observed on the surface of solidified shell contact to the copper plate.

The chemical compositions of molten steels were adjusted as shown in Table 1 and the experimental conditions are listed in the same table.

The solidified shell was machined into its longitudinal direction and at the central width of the shell, and then the shell thickness was measured. A sample for microscopy was taken from a part of longitudinal cross section of the shell. And it was polished to a mirror level, etched with an aquasolution saturated with picric acid, and subsequently observed with an optical microscope.

In order to investigate the characteristics of ripple marks, pitch, depth and curvature radius were measured using a method as shown in Fig. 2. The pitch, $L_{r}$, is a distance between two neighboring depressions. The depth, $D_{r}$, is a distance from a shell surface to a tip of ripple mark exposed

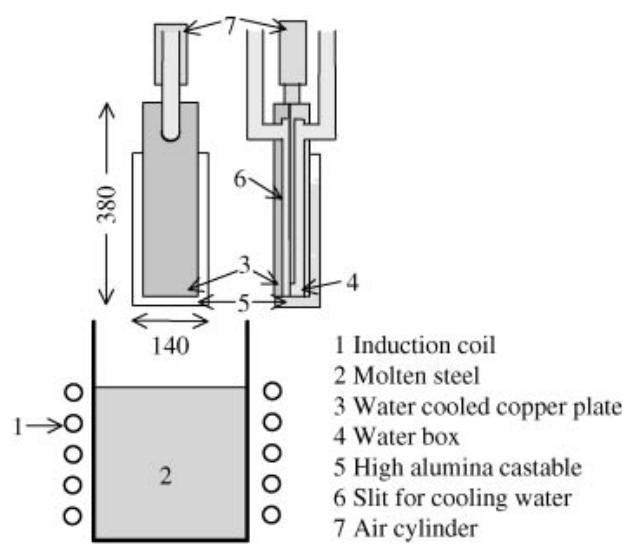

Fig. 1 Schematic diagram of experimental apparatus for dipping test.

Table 1 Chemical compositions of steels used for the dipping test and experimental conditions.

\begin{tabular}{|c|c|c|c|c|c|c|}
\hline \multirow{3}{*}{$\begin{array}{l}\text { Molten } \\
\text { steel }\end{array}$} & \multirow{2}{*}{$\begin{array}{l}\text { Chemical } \\
\text { composition } \\
\text { (mass\%) }\end{array}$} & \multicolumn{5}{|c|}{ C: $0.005,0.05,0.12,0.30,0.70$} \\
\hline & & $\begin{array}{c}\mathrm{Si} \\
<0.02\end{array}$ & $\begin{array}{l}\mathrm{Mn} \\
0.20\end{array}$ & $\begin{array}{c}\mathrm{P} \\
0.01\end{array}$ & $\begin{array}{c}S \\
0.01\end{array}$ & $\begin{array}{c}\text { sol. Al } \\
0.05-0.10\end{array}$ \\
\hline & Superheat $(\mathrm{K})$ & \multicolumn{5}{|c|}{30,50 and 90} \\
\hline \multicolumn{3}{|c|}{ Dipping speed (mm/s) } & \multicolumn{4}{|c|}{14} \\
\hline \multicolumn{3}{|c|}{ Dipping length (mm) } & \multicolumn{4}{|c|}{ ca. 250} \\
\hline \multicolumn{3}{|c|}{ Cooling water flow rate $(\ell / \mathrm{min})$} & \multicolumn{4}{|c|}{90} \\
\hline
\end{tabular}

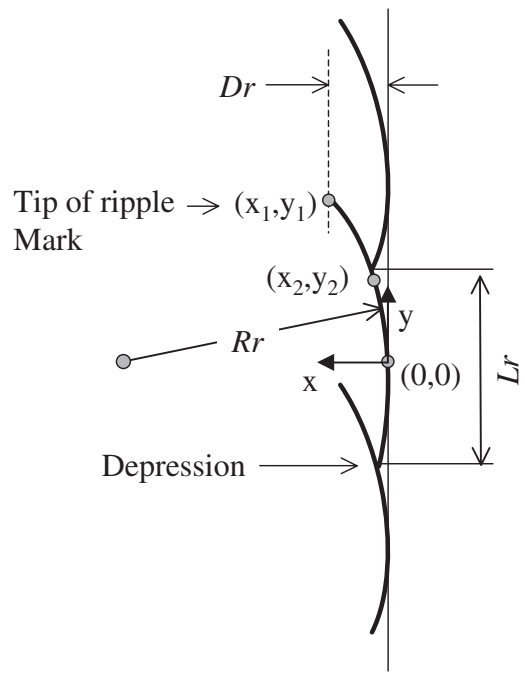

Fig. 2 Investigation method of ripple mark characteristics.

by etching. The curvature radius, $R_{r}$, of a ripple mark is approximately expressed by a radius of a single circle inscribing an outer line in a cross section of the ripple mark by using three points shown in Fig. 2 . These values are averages of measurements of more than 10 ripple marks. Also the thickness of the shells was measured.

\section{Results and Discussion}

\subsection{Influence of carbon content on surface quality of solidifying shell}

Figure 3 shows the outer and inner surfaces of solidified shells for different carbon steels: (a) ultra-low carbon steel (0.005 mass\% C), (b) low carbon steel (0.044 mass\% C), (c) hypo-peritectic carbon steel $(0.116$ mass $\% \mathrm{C})$, (d) hyperperitectic carbon steel $(0.304$ mass $\%$ C) and (e) high carbon steel (0.678 mass\% C). For an ultra-low carbon steel and a hypo-peritectic carbon steel the rough surfaces are clearly revealed in both outer and inner surfaces of the shells.

In contrast, for a low carbon steel, a hyper-peritectic carbon steel and a high carbon steel flat surfaces are exhibited in the both surfaces in comparison with the above two steels.

\subsection{Carbon content dependence of the unevenness of solidifying shell growth}

Figure 4 shows profiles of the shell thickness in the longitudinal cross sections of solidified shells for the five steels. The uneven shell thickness is revealed anomalously in the ultra-low carbon steel and the hypo-peritectic carbon steel similar to the surface roughness.

Figure 5 shows the thickness of solidified shell vs. distance from the upper tip of solidified shell for different carbon steels. Shells of the ultra-low carbon steel and the hypoperitectic carbon steel grow more unevenly in comparison with those of other steels. For the hypo-peritectic carbon steel, at the early stage of solidification the shell grows unevenly, while for the ultra-low carbon steel the shell grows evenly until around 10 seconds from the start of dipping, but after the time the anomalous uneven shell appears.

In contrast, for the low carbon steel and the high carbon steel the shell grows in flat and the thickness are similar to 


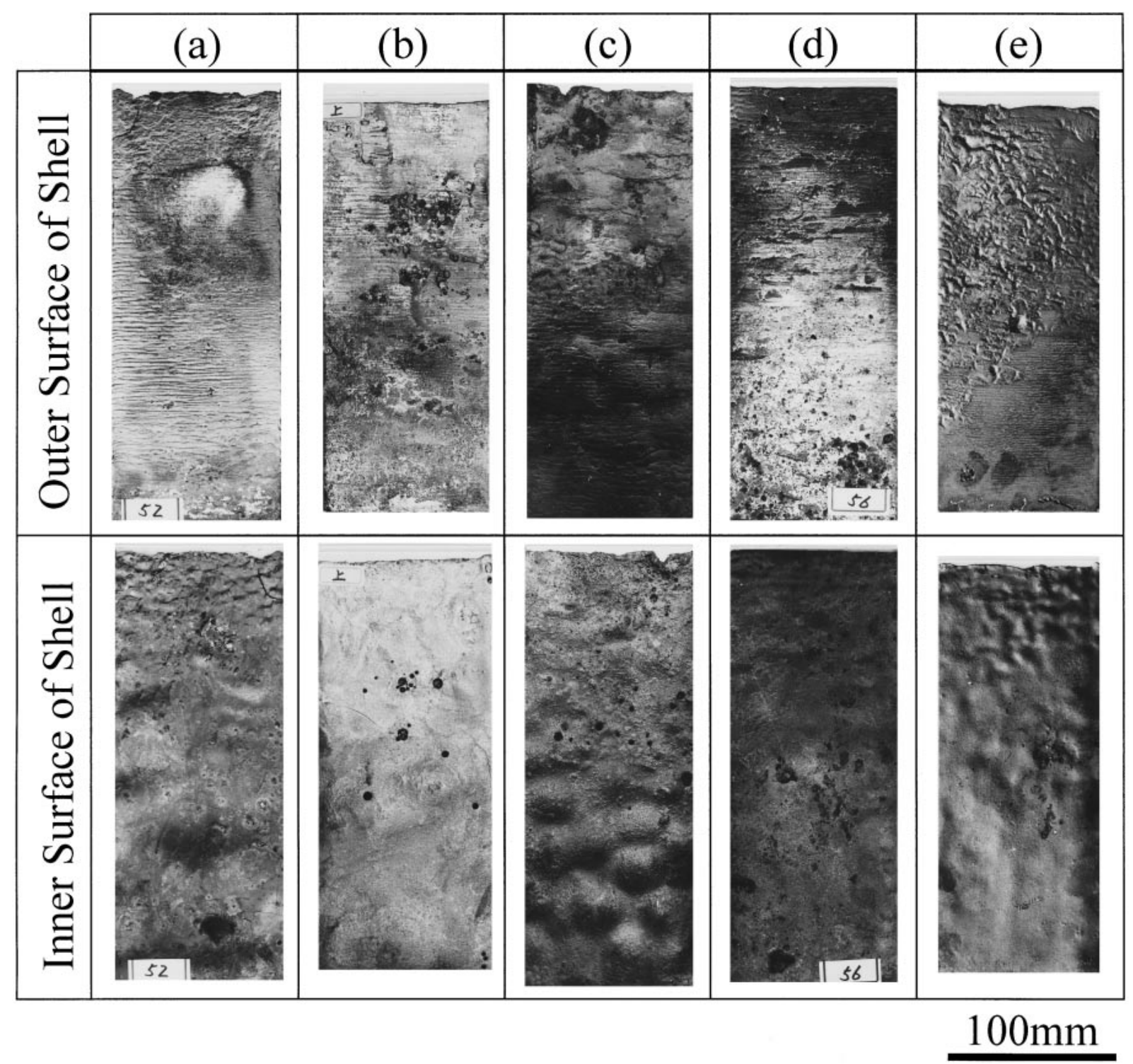

Fig. 3 Appearance of outer and inner surfaces of the solidified shells [(a) ultra low carbon steel (0.005 mass\% C), (b) low carbon steel $(0.044$ mass \% C), (c) hypo-peritectic carbon steel $(0.116$ mass \% C), (d) hyper-peritectic carbon steel $(0.304$ mass $\%$ C) and (e) high carbon steel (0.678 mass\% C)].

that of the ultra-low carbon steel. However, although for the hyper-peritectic carbon steel the shell grows evenly, in thinnest thickness among those steels.

The shell thickness $(\mathrm{mm}), D_{s}$, is experimentally expressed by $D_{S}=K_{S} \sqrt{t}$, here, $K_{S}$ is the solidification constant $(\mathrm{mm} /$ $\min ^{1 / 2}$ ) and $t$ is the solidification time $(\min )$.

The instantaneous $K_{S}$ was obtained by reverse calculation using the data of $D_{s}$ and $t$ in Fig. 5. Also the unevenness of shell thickness was expressed by the standard deviation of $K_{S}$. The average value and standard deviation of $K_{S}$ are calculated and shown in Figs. 6(a) and (b) against carbon content.

On the other hand, the $K_{S}$ can be given by the following equation derived from heat transfer analysis under the conditions that temperatures in a mold are kept constant when a pure liquid metal crystallizes. ${ }^{12)}$

$$
\frac{K_{S}}{2 \sqrt{\alpha}} \exp \left(\frac{K_{S}^{2}}{4 \alpha}\right) \operatorname{erf}\left(\frac{K_{S}}{2 \sqrt{\alpha}}\right)=\left(T_{m}-T_{s}\right) \frac{C_{p}}{H_{f} \sqrt{\pi}}
$$

where $\alpha$ is the thermal diffusivity $\left(\mathrm{m}^{2} / \mathrm{s}\right), C_{p}$ : the specific heat capacity $(\mathrm{kJ} / \mathrm{kg} \cdot \mathrm{K}), H_{f}$ : the latent heat $(\mathrm{kJ} / \mathrm{kg}), T_{m}$ : the melting temperature $(\mathrm{K})$, and $T_{s}$ is the interfacial temperature (K) between a solidifying shell and a mold.

The $K_{S}$ is calculated substituting the following values of physical properties into eq. (1): $\alpha$ is given by Nishi et al. ${ }^{13)}$ such as $0.672 \times 10^{-5}, 0.682 \times 10^{-5}$ and $0.629 \times 10^{-5} \mathrm{~m}^{2} / \mathrm{s}$ at $1573 \mathrm{~K}$ for an ultra-low carbon steel, a low carbon steel and a medium carbon steel, respectively, and $C_{p}=0.67 \mathrm{~kJ} / \mathrm{kg} \cdot \mathrm{K}$, $H_{f}=272 \mathrm{~kJ} / \mathrm{kg}, T_{m}$ is given by the liquidus temperature calculated from the chemical composition, and a temperature difference, $T_{m}-T_{s}$, is assumed to be $200 \mathrm{~K}$, because the surface temperature of a shell in a continuous casting mold is predicted about $1573 \mathrm{~K}$. The calculated $K_{S}$ is around $18 \mathrm{~mm} /$ $\min ^{1 / 2}$ and is a little decreased with carbon content.

In contrast, when the unevenness of the shell thickness is expressed by the standard deviation of the shell thickness, the unevenness reveals two peaks at the ultra-low carbon steel and the hypo-peritectic carbon steel as shown in Fig. 6(a). 


\section{Upper Tip of Shell Bottom End of Chill Plate}

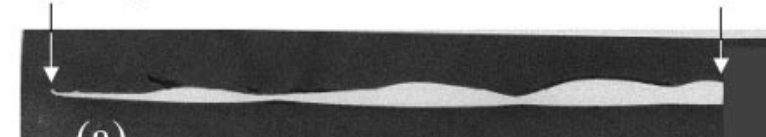

(a)

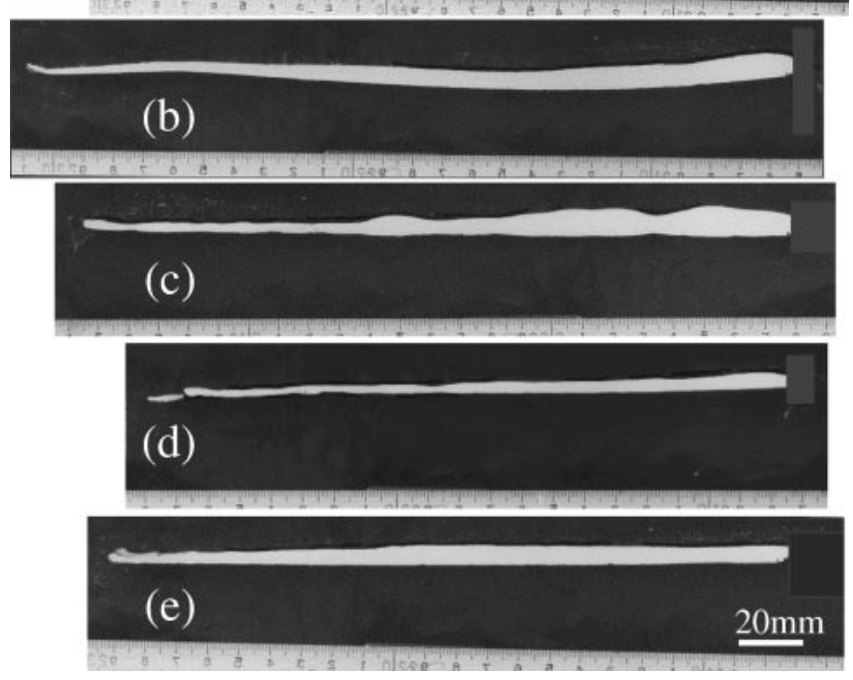

Fig. 4 Shell thickness profiles in the longitudinal cross section along the dipping direction [(a) ultra low carbon steel $(0.005$ mass \% C), (b) low carbon steel $(0.044$ mass\% $\quad$ C), (c) hypo-peritectic carbon steel $(0.116$ mass\% C), (d) hyper-peritectic carbon steel $(0.304$ mass\% C) and (e) high carbon steel $(0.678$ mass\% C)].

Solidification Time, $t / \mathrm{s}$

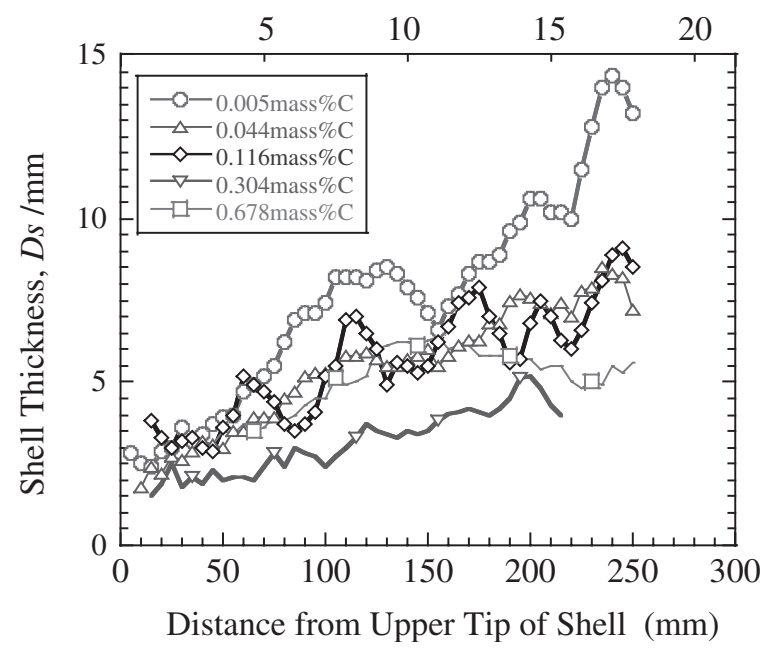

Fig. 5 The shell thickness in the dipping direction for various carbon steels.

\subsection{Characteristics of Ripple Mark}

Tomono et al. ${ }^{9)}$ have studied the shape of meniscus in the solidifying steel shells containing 0.18 to 0.22 mass $\%$ carbon with a bottom pouring casting test. The meniscus shape was observed through a silica glass putting into a part of mold when a liquid metal level is rising up and passing through the glass. Fifteen pictures of the meniscus shape were totally taken at five pictures every second, and the averaged curvature was determined using the pictures. And they examined the pitch, the depth of the ripple mark formed on the ingot.

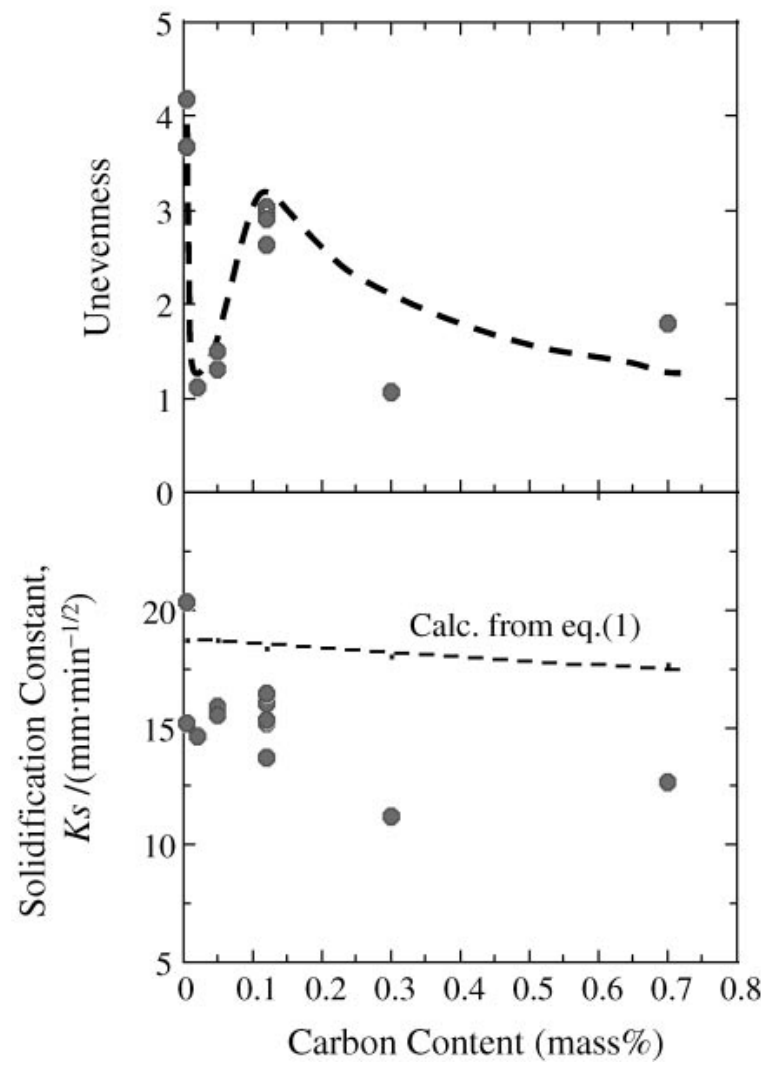

Fig. 6 Influence of carbon content on the unevenness of shell thickness and the solidification constant, $K_{S}$.

We measured the pitch, the depth and the curvature radius of the ripple marks similarly and compared them with the Tomono's observation measured at an upward speed of 8 and $12 \mathrm{~mm} / \mathrm{s}$ and different atmospheres such as air, hydrogen and argon gas.

\subsubsection{Pitch of ripple mark}

Solidification structures of the shells for the ultra-low carbon steel and the hypo-peritectic carbon steel are shown in Fig. 7. Arrows in this figure show the ripple marks.

Figure 8 shows the relationship between the pitch of ripple mark and the carbon content in solidifying shell. For comparison, Tomono's data measured under the air atmosphere and a copper chill was plotted in this figure.
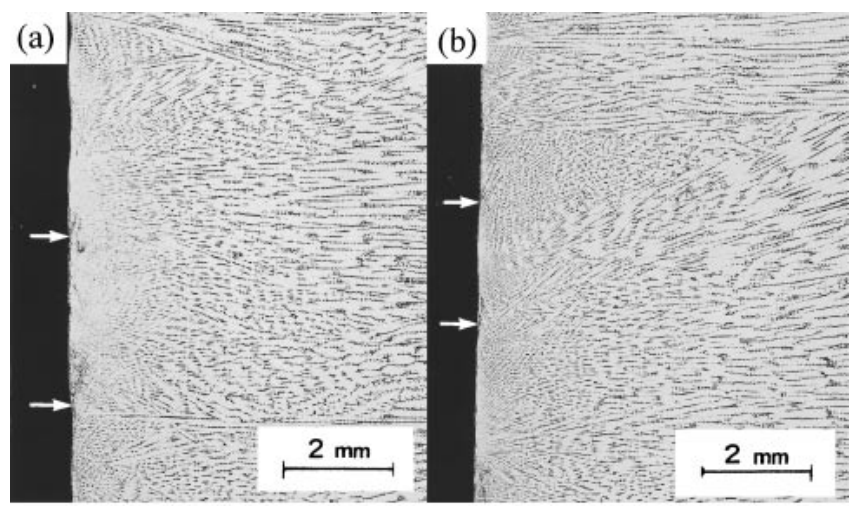

$\begin{array}{ll}\text { (a) Ultra Low C Steel } & \text { (b) Hyper-Peritectic C Steel }\end{array}$

Fig. 7 Examples of ripple marks [(a) ultra-low carbon steel (0.005 mass\% C) and (b) hyper peritectic carbon steel (0.304 mass\% C)]. 


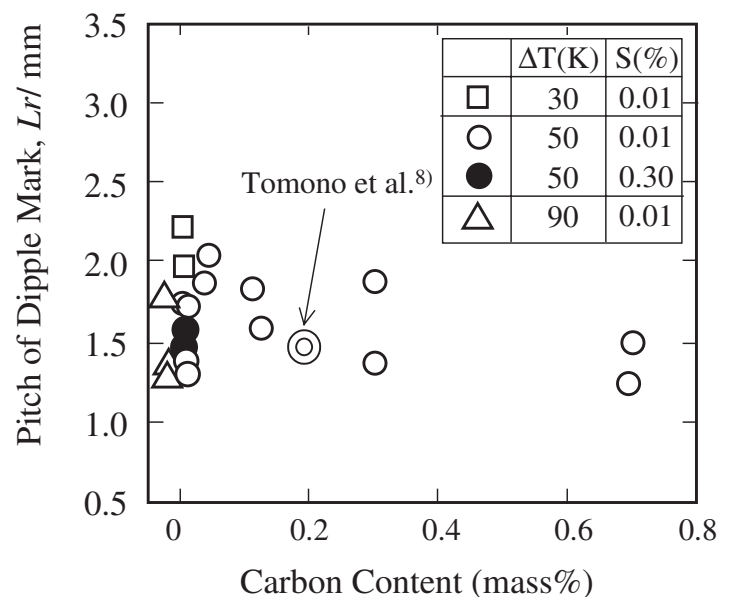

Fig. 8 Relationship between pitch of ripple mark and carbon content.

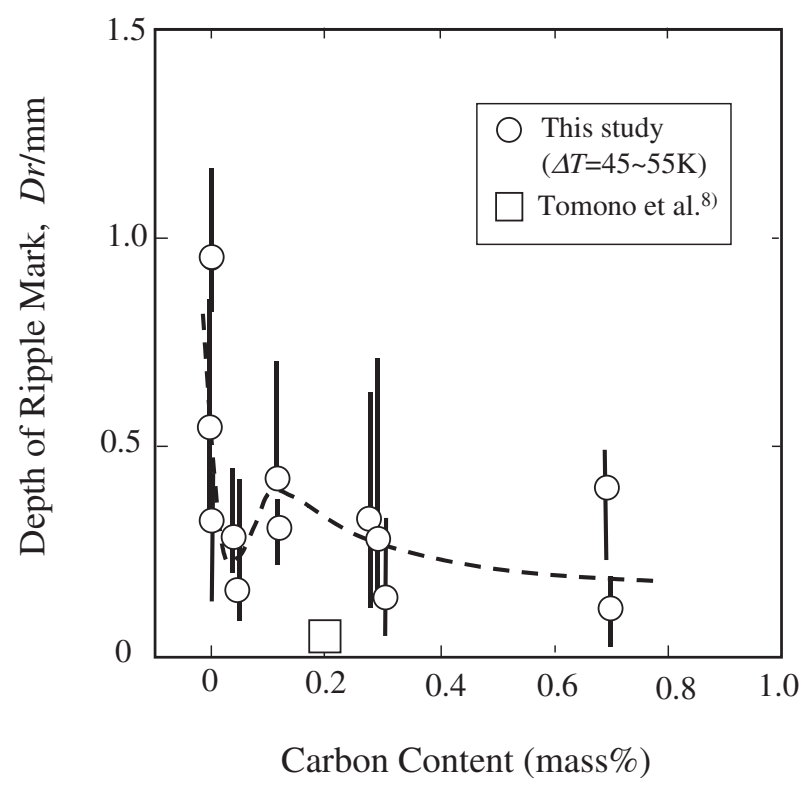

Fig. 9 Relationship between depth of ripple mark and carbon content.

\subsubsection{Depth of ripple mark}

Figure 9 shows the relationship between the depth of ripple mark and the carbon content in solidifying shell when the superheat ranged from 45 to $55 \mathrm{~K}$. The ultra-low carbon steel and the hypo-peritectic carbon steel have anomalously deeper ripple marks than those of other carbon steels.

The data measured by Tomono et al. using a copper chill in air is smaller than our observations.

The depth of ripple mark is remarkably affected by superheat in molten steel during dipping test. Figure 10 demonstrates the influence of superheat on the depth of ripple mark for the ultra-low carbon steel. Clearly the higher superheat forms the shallower ripple mark.

\subsubsection{Shape of ripple mark}

The curvature radius of ripple mark was independent of the carbon content in this study. The curvature radius is shown in Fig. 11 against the depth of ripple mark.

It is thought that the shape of ripple mark expresses a meniscus form of molten steel level. Tomono et al. ${ }^{9)}$ have showed that the shape of meniscus can be estimated

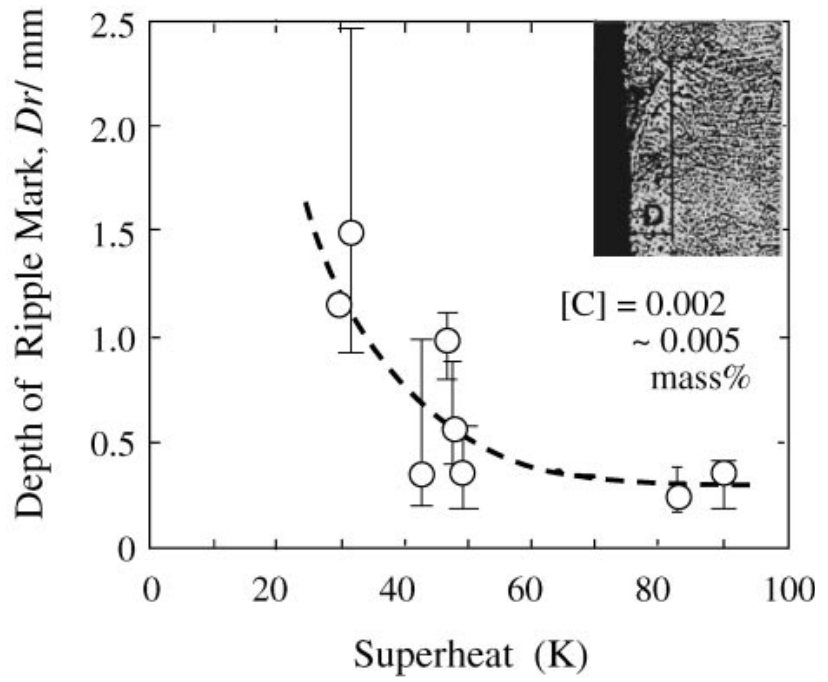

Fig. 10 Influence of superheat on the depth of ripple mark for ultra-low carbon steel shell.

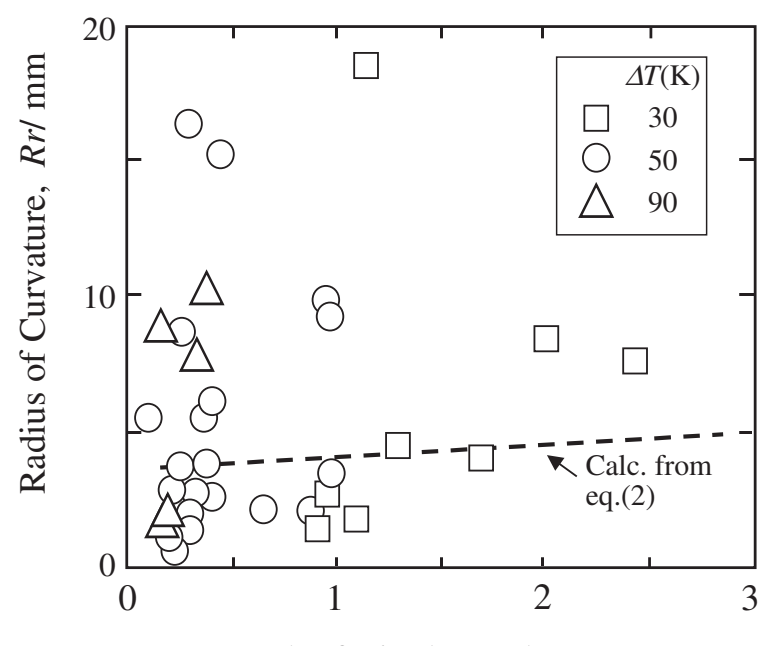

Depth of Ripple Mark, $\mathrm{Dr} / \mathrm{mm}$

Fig. 11 Relationship between depth of ripple mark and curvature radius.

accurately by the following equation. The shape of any liquid cylinder in mechanical equilibrium, i.e., where the inner pressure $(=\rho g y)$ is balanced by capillarity pressure $\left(=\sigma_{S} / R_{r}\right)$ can be theoretically determined from $\left.{ }^{12}\right)$

$$
\begin{aligned}
x-x_{0}= & -\sqrt{2 a^{2}-y^{2}}+(a / \sqrt{2}) \\
& \cdot \ln \left\lfloor\left(a \sqrt{2}+\sqrt{2 a^{2}-y^{2}}\right) / y\right\rfloor
\end{aligned}
$$

where, $a$ is the capillary constant $\left[a=\sqrt{2 \sigma_{S} / \rho g}\right], \sigma_{S}$ is the surface energy $(\mathrm{N} / \mathrm{m})$ of molten steel, $g$ is the acceleration of gravity and $\rho$ is the density $\left(\mathrm{kg} / \mathrm{m}^{3}\right)$ of molten steel.

In order to investigate the effect of surface energy on the meniscus shape, the surface energies of these steels are given by $1.456 \mathrm{~N} / \mathrm{m}^{15)}$ and $0.994 \mathrm{~N} / \mathrm{m}^{16)}$ for the ultra-low carbon steel and a high sulfur (0.1 mass \%) low carbon steel, respectively, and the meniscus shape was calculated with eq. (2). The calculated meniscus shapes of those steels are shown in Fig. 12. For the case of the high sulfur steel, the calculated shape is different from that of the ultra-low carbon 
(a) $\sigma_{S}=1.457 \mathrm{~N} / \mathrm{m}$

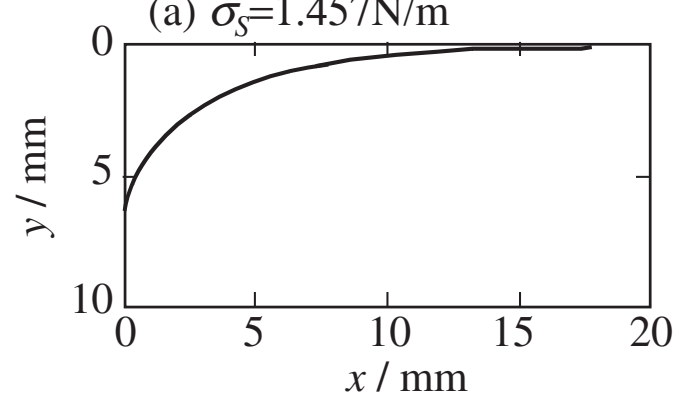

(b) $\sigma_{S}=0.995 \mathrm{~N} / \mathrm{m}$

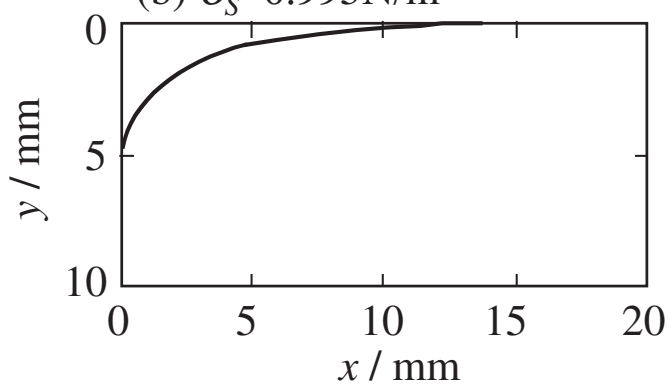

Fig. 12 Influence of interfacial energy on the calculated meniscus shape of molten steel [(a) $\sigma_{S}=1.5 \mathrm{~N} / \mathrm{m}$ and (b) $\left.\sigma_{S}=0.9 \mathrm{~N} / \mathrm{m}\right]$.

steel. However, since there is a very small dependence of carbon content on the surface energy, the curvature radii for different carbon steels are nearly equal one another.

The curvature radius was approximately determined by a radius of a single circle inscribing three points on the calculated line of meniscus shape: a points contacting a chill, a point, e.g. $0.5 \mathrm{~mm}$, corresponding to a depth of a ripple mark and a mid-point between the two points. In Fig. 11 a dotted line shows the relation between calculated curvature radii and the depth of ripple mark calculated from eq. (2).

\subsection{Solidification in meniscus zone}

Solidification in the meniscus is calculated with a simple model as shown in Fig. 13. The effect of the shape of meniscus on the solidification was replaced by changing thermal resistance. The calculation area was selected as same as one in Fig. 12. In this model, boundary conditions are assumed that the heat energy is extracted from only the copper plate, and is not extracted at the molten steel level and at a distance of $10 \mathrm{~mm}$ from the molten steel level.

Next, the shape of meniscus is given by the calculated one in Fig. 12(a), and the heat fluxes between a copper plate wall and a solidifying shell were given as shown in Fig. 13(b). The heat fluxes, $Q_{M 0}$, in contact zone where a molten steel contacts to the copper plate, and $Q_{M x}$, in meniscus zone, the molten steel separating from the copper plate, is given by

$$
\begin{aligned}
Q_{M 0} & =h_{0} \cdot \Delta T \\
Q_{M x} & =\left[1 /\left(1 / h_{0}+d_{M} / \lambda_{G}\right)\right] \cdot \Delta T
\end{aligned}
$$

where, $h_{0}$ is the overall heat transfer coefficient $\left[\mathrm{W} /\left(\mathrm{m}^{2} \cdot(\mathrm{K})\right]\right.$ in the contact zone, $\Delta T\left(=T_{M}-T_{S}\right)$ : the temperature difference $(\mathrm{K})$ between molten steel in the meniscus and contact zones and the copper plate, $d_{M}$ : the thickness (m) of a gap between a copper plate and a solidifying shell, and $\lambda_{G}$ is the thermal conductivity $[\mathrm{W} /(\mathrm{m} \cdot \mathrm{K})]$ of the air, which was (a)

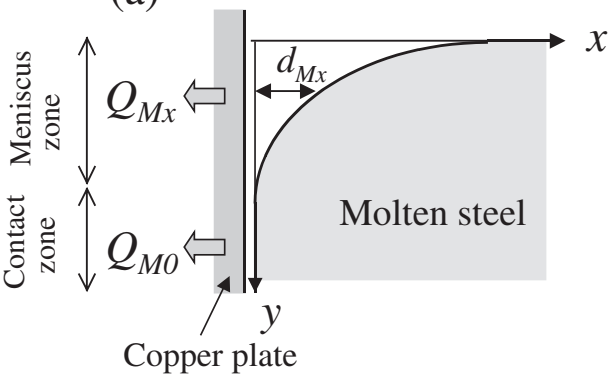

(b)

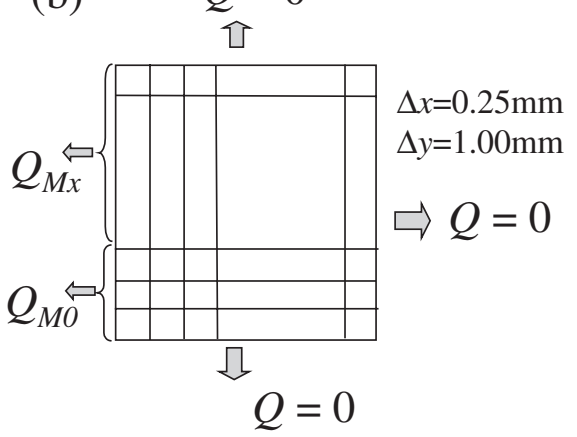

Fig. 13 Analytical model of solidification in the meniscus zone.

given by $0.0573 \mathrm{~W} /(\mathrm{m} \cdot \mathrm{K})$ at $1073 \mathrm{~K}$.

The above thermal boundary conditions are summarized in Fig. 13(b).

The heat flux in the zone where a shell contacts a copper plate wall was adjusted to meet the calculated shell thickness for a solidification time of $0.2 \mathrm{~s}$ to form one ripple mark to the observed shell thickness at a superheat of $30 \mathrm{~K}$. The heat flux, $Q_{M 0}$, in the contact zone was given to be $4.823 \times 10^{6} \mathrm{~W} / \mathrm{m}^{2}$.

The calculated shell thickness in the meniscus zone is shown in Fig. 14 for a superheat of $30 \mathrm{~K}$ and $50 \mathrm{~K}$. The meniscus shape was given by that in Fig. 12(a). The higher superheat can form the shallower ripple mark.

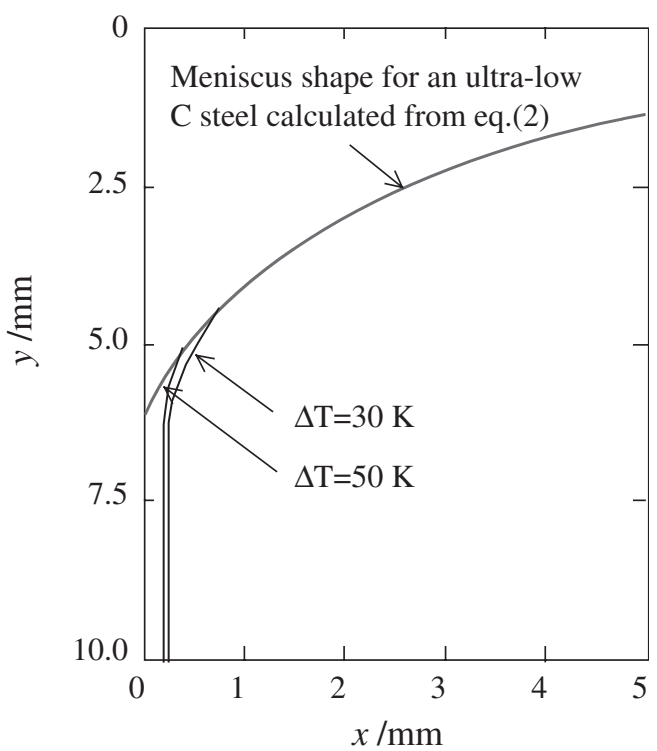

Fig. 14 Influence of the superheat in molten steel on the calculated meniscus shell thickness. 


\subsection{Strain induced in a shell caused by solidification shrinkage and $\delta / \gamma$ transformation during solidification}

In order to estimate strain induced in a solidifying shell in the initial solidification, the rate, $R_{\text {Sol }}$, of solidification shrinkage and the rate, $R_{\delta / \gamma}$, of $\delta / \gamma$ transformation were calculated.

The microsegregation and the $\delta / \gamma$ transformation during solidification of $\mathrm{Fe}-\mathrm{C}$ alloys were calculated with a model as shown in Fig. 15 similar to that made by Ueshima et al. ${ }^{17)}$ The $R_{\delta / \gamma}$ is governed by diffusion of carbon in $\delta$-iron and $\gamma$-iron in an interdendritic region.

$$
\begin{aligned}
& \partial C / \partial t=D_{i} \cdot \partial^{2} C / \partial x^{2} \quad(\mathrm{i}=\delta \quad \text { or } \gamma \text {-iron }) \\
& t=0, \quad C=C_{0} \\
& t>0, \quad C_{\gamma} / C_{\ell}=k_{\gamma / \ell} \quad \text { at } \quad x=x_{\gamma / \ell} \\
& C_{\delta} / C_{\gamma}=k_{\delta / \gamma} \quad \text { at } \quad x=x_{\delta / \gamma} \\
& t>0, \quad \partial C / \partial x=0 \quad \text { at } \quad x=0 \quad \text { and } d_{1}
\end{aligned}
$$

where $C$ is the carbon content (mass $\%), C_{0}$ : the initial carbon content (mass\%), $D_{i}$ : the diffusion coefficient $\left(\mathrm{mm}^{2} / \mathrm{s}\right)$ of carbon in iron of phase $\mathrm{i}, k_{\gamma / \ell}$ and $k_{\delta / \gamma}$ : the equilibrium of partition ratios (-) of carbon at the $\gamma / \ell$ and $\delta / \gamma$ interfaces, $d_{1}$ : the primary dendrite arm spacing $(\mathrm{mm}), x$ : the distance $(\mathrm{mm})$ from a reference point in a half of $d_{1}, x_{\gamma / \ell}$ and $x_{\delta / \gamma}$, the distance $(\mathrm{mm})$ between the $\delta / \ell$ interface at the start of the peritectic reaction and the $\gamma / \ell$ and the $\delta / \gamma$ interfaces, respectively, and $t$ is the diffusion time (s).

Equation (5) was solved by a finite difference approximation under initial and boundary conditions [eqs. (6)-(8)]. In this study, $d_{1}$ was given by $0.2 \mathrm{~mm}$, which is a primary arm spacing of dendrite near a surface in continuously cast slab,

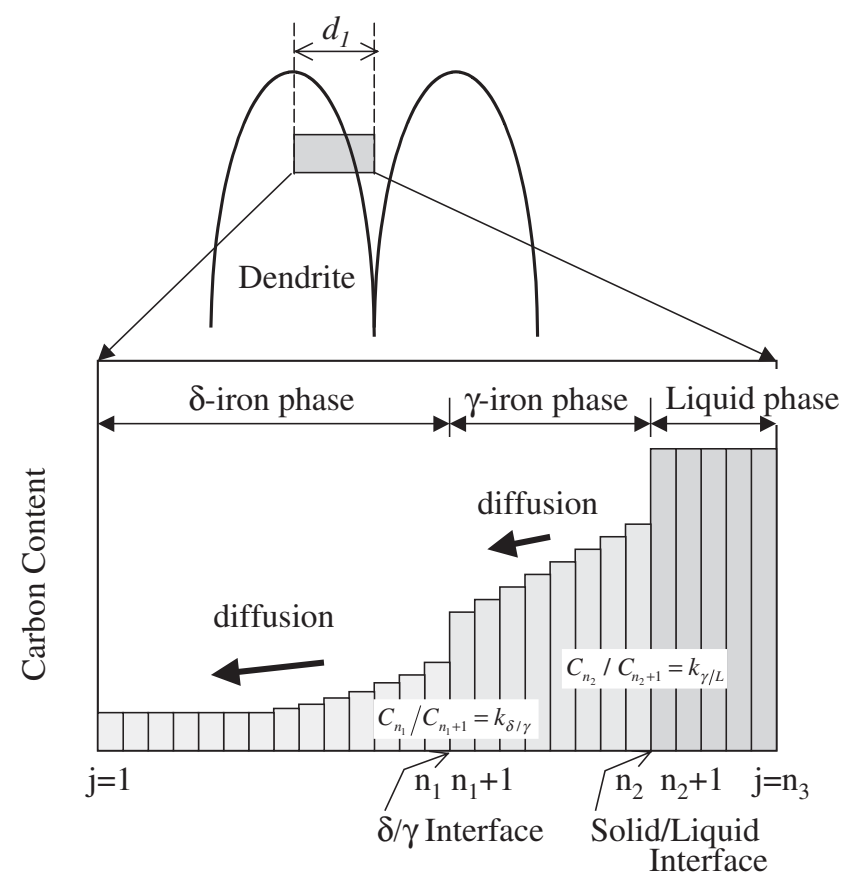

Fig. 15 Calculation model for formation of microsegregation and $\delta / \gamma$ transformation on cooling.

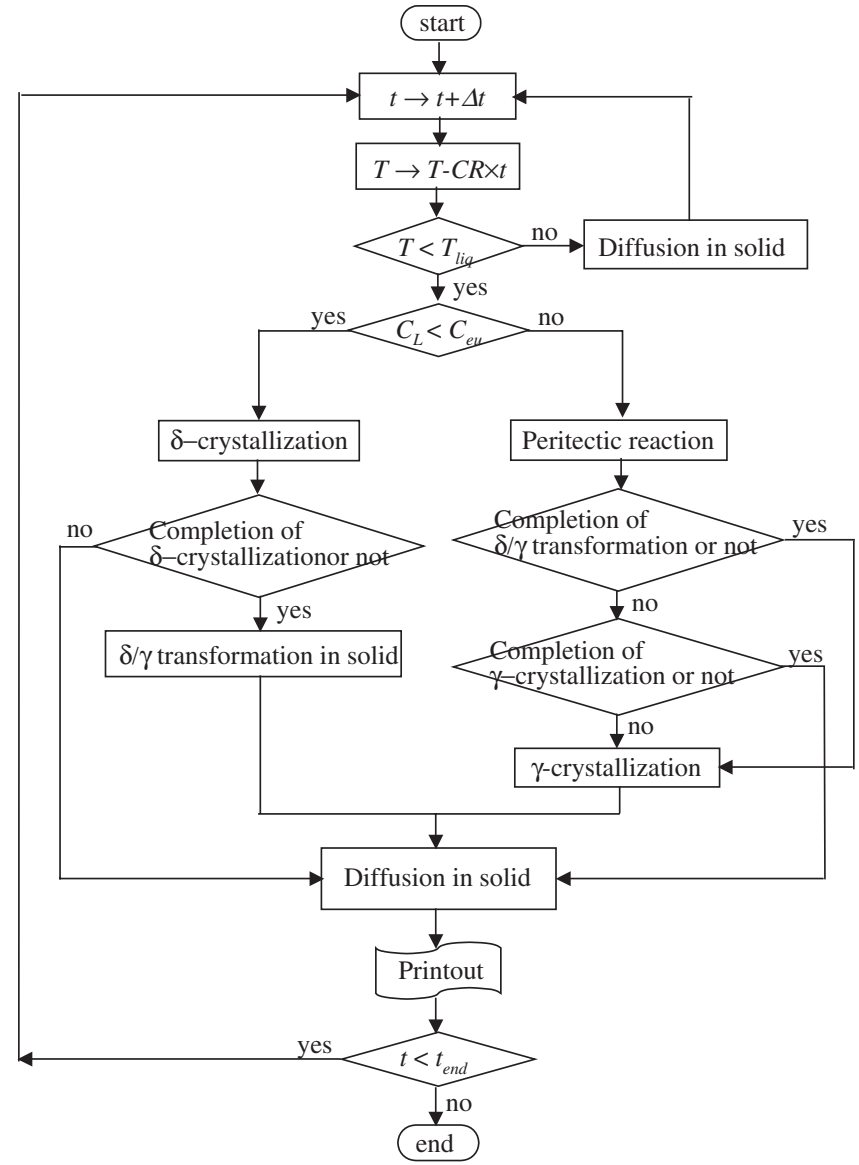

Fig. 16 Flow chart of calculation of microsegregation and $\delta / \gamma$ transformation on cooling.

and the interdendritic region was divided into 50 elements. Time increment, $\Delta t$, is taken to be $0.00001 \mathrm{~s}$. The equilibrium partition ratios and diffusion coefficients are in the literature. ${ }^{17)}$ Since perfect mixing is assumed in liquid phase, the carbon content is uniform.

The flow chart of calculation is shown in Fig. 16. First, the temperature, $T$, in the interdendritic region is given by a cooling curve and compared with the liquidus temperature, $T_{\mathrm{L}}$, given by chemical composition of the liquid phase. When the $T$ is lower than the $T_{\mathrm{L}}$ and the carbon content in the liquid phase is smaller than the carbon content $\left(C_{\text {eu }}\right)$ at which the crystallization of $\gamma$-iron begins to occur, $\delta$-iron crystallizes. The carbon atom is distributed into $\delta$-iron and liquid steel phases assuming equilibrium solidification.

Second, when the carbon content $\left(C_{\mathrm{L}}\right)$ in liquid phase reaches the $C_{\mathrm{eu}}$, the peritectic reaction begins to occur. Just after the start of peritectic reaction when the $\gamma$-iron crystallization and the $\delta / \gamma$ transformation take place simultaneously, the carbon content $\left(C_{\gamma}\right)$ in a mesh of solidified $\gamma$-iron in the nearest neighborhood of the $\gamma /$ liquid steel interface is determined to make the ratio of carbon content in the meshes on both sides of the $\gamma /$ liquid steel interface equal to the equilibrium partition ratio. Also, the $\delta / \gamma$ interface shifts one mesh to $\delta$-iron phase side and $\gamma$-iron phase is extended when the ratio of carbon content in a $\delta$-iron mesh to that in a $\gamma$-iron mesh at the $\delta / \gamma$ interface becomes equal to the equilibrium partition ratio. 
Finally, if the $\delta$-iron is consumed completely for $\delta / \gamma$ transformation, the $C_{\mathrm{L}}$ becomes larger than the $C_{\text {eu }}$, and the $T$ becomes also lower than the $T_{\mathrm{L}}$, then $\delta$-iron crystallization mode is changed to $\gamma$-iron crystallization mode, and the $\gamma$ iron crystallizes.

Shin et al. ${ }^{18)}$ conducted a hot tensile test and deformed a test piece to a failure after being melted and then solidified in a testing machine. They showed that the tensile strength begins to arise in a fraction solid of 0.6 to 0.7 .

At the initial stage of solidification the shell strength is too low, and hence the shell is easy to be deformed by thermal stress and $\delta / \gamma$ transformation stress. In this study, in the case of peritectic reaction formed during solidification, the volume, $V_{\mathrm{tr}}$, and the rate, $R_{\mathrm{tr}}$, of transformation include both the solidification and the $\delta / \gamma$ transformation formed during a fraction solid of 0.7 to 1.0. On the other hand, in the case of no peritectic reaction, the $V_{\mathrm{tr}}$ and the $R_{\mathrm{tr}}$ include only solidification shrinkage.

Two cooling rate was selected, $5 \mathrm{~K} / \mathrm{s}$ and $0.5 \mathrm{~K} / \mathrm{s}$. A cooling rate of $5 \mathrm{~K} / \mathrm{s}$ corresponds to that at a slab surface in a continuous casting mold and a cooling rate of $0.5 \mathrm{~K} / \mathrm{s}$ is assumed as an example of extremely mild cooling.

The calculated volume and rate, $R_{\mathrm{tr}}$, at a cooling rate of 5 and $0.5 \mathrm{~K} / \mathrm{s}$ are plotted in Fig. 17 against carbon content. The calculated volume is normalized by dividing an initial volume and expressed by $V_{\mathrm{tr}} / V_{0}$. The $V_{\mathrm{tr}} / V_{0}$ is remained constant before initiation of $\delta / \gamma$ transformation and after completion of $\delta / \gamma$ transformation as shown in Fig. 17(a). And it increases with carbon content of 0.08 to 0.18 mass\% C,

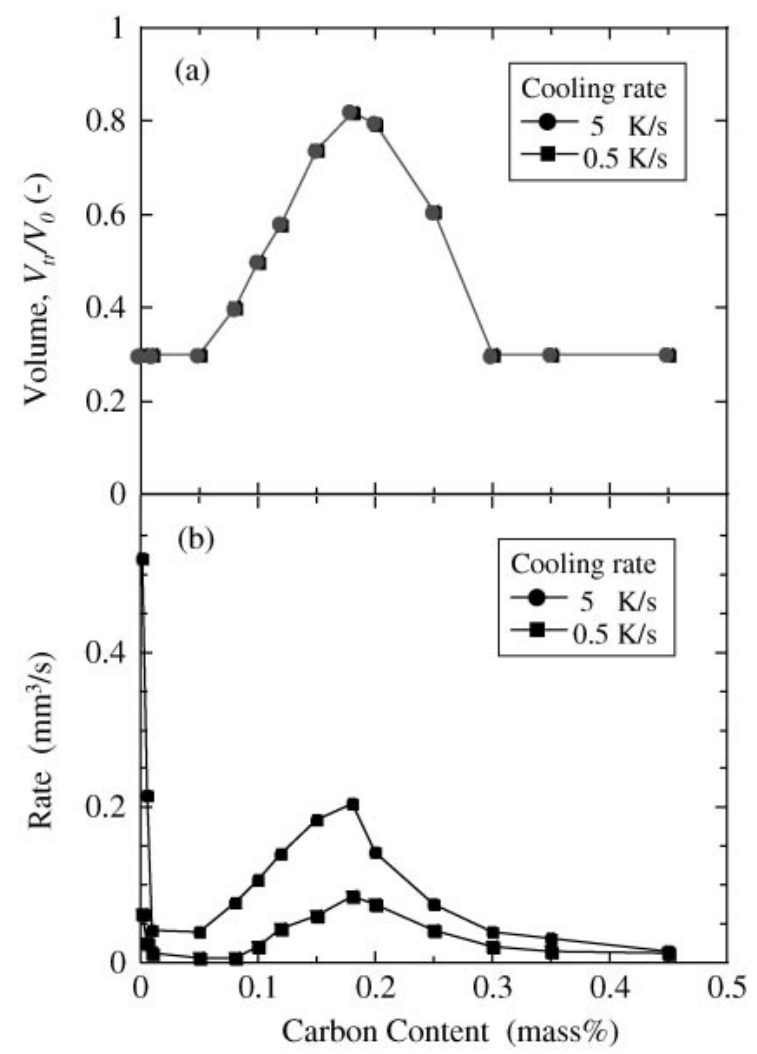

Fig. 17 Influence of carbon content on the calculated rate and volume of solidification and $\delta / \gamma$ transformation occurring in a solid fraction 0.7 to 1.0. reaches a peak, and subsequently decreases with carbon content of 0.18 to 0.35 mass $\%$.

On the other hand, the $R_{\mathrm{tr}}$ reveals two peaks in the ultralow carbon steel and the hypo-peritectic carbon steel, and has a minimum in approximately 0.04 mass \% C. Furthermore, the rate is extremely decreased by decreasing cooling rate. Also, the $R_{\mathrm{tr}}$ is decreased with decreasing cooling rate.

A stress-strain relation at elevated temperatures is given by ${ }^{19)}$

$$
\sigma=F \cdot \varepsilon^{n} \cdot \dot{\varepsilon}^{m} \cdot \exp (-Q / R T)
$$

where $\sigma$ is the stress $(\mathrm{MPa}), \varepsilon$ : the strain $(-), \dot{\varepsilon}$ : the strain rate $\left(\mathrm{s}^{-1}\right), n$ : the strain exponent $(-), m$ : the strain rate exponent (-), $Q$ : the activation energy $(\mathrm{J} / \mathrm{mol}), R$ : the gas constant and $T$ is the temperature $(\mathrm{K})$.

The strain generated in a shell during solidification is expressed as $\varepsilon_{\text {sol }}+\varepsilon_{\delta / \gamma}$, where $\varepsilon_{\text {sol }}$ is the strain due to the solidification shrinkage and $\varepsilon_{\delta / \gamma}$ is the strain due to $\delta / \gamma$ transformation, and the $\varepsilon_{\text {sol }}+\varepsilon_{\delta / \gamma}$ is related to a volume change caused by transformation. The strain rate is assumed to be an average during a fraction solid of 0.7 to 1.0 , and corresponds to a sum of the rates of the solidification and the $\delta / \gamma$ transformation. A product between the transformation volume and the transformation rate is corresponding to a stress expressed by eq. (9). In this study, a product between the transformation volume and the transformation rate is given by $\left(V_{\mathrm{tr}} / V_{0}\right) \cdot R_{\mathrm{tr}}$, which is called stress index. The stress index vs. carbon content is shown in Fig. 18 for different cooling rate, exhibiting two peaks in the ultra-low carbon steel and the hypo-peritectic carbon steel and decreasing with decreasing cooling rate.

Consequently, the $\delta / \gamma$ transformation occurring during solidification in the higher fraction solid is confirmed to lead to the greater shell deformation and the larger air gap, resulting in an uneven shell growth with some deflection and anomalous reduction of heat flux in a mold, which in turn causes local recalescence of the deflected portion of the shell to reduce the shell strength.

The analytical results such that the stress induced in a shell

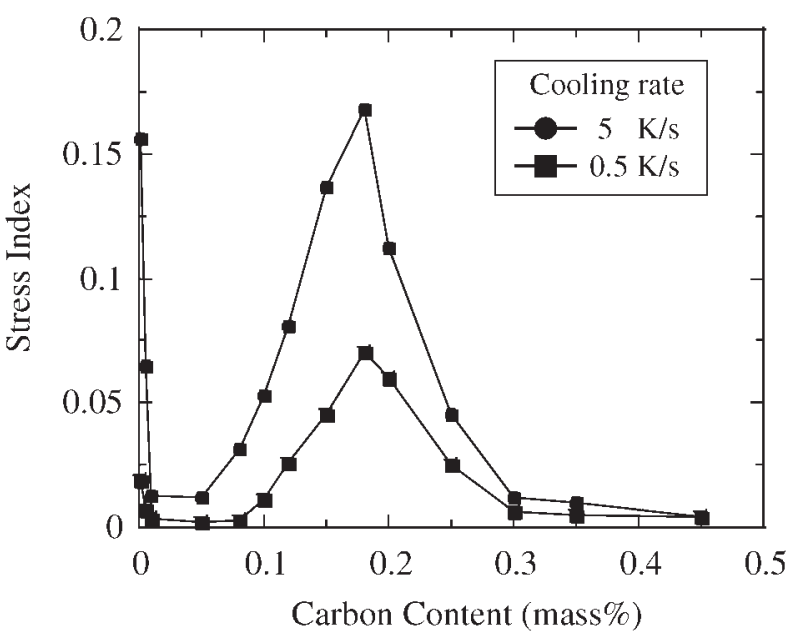

Fig. 18 Influence of carbon content on the calculated stress index, a product of the rate and volume of solidification and $\delta / \gamma$ transformation occurring in a solid fraction of 0.7 to 1.0 . 
is reduced by a mild cooling gives the understanding of the reason for the effect of the mild cooling in a mold on the prevention of longitudinal surface crack in the hypoperitectic carbon steel.

\section{Conclusions}

A dipping test using a copper plate cooled by water was performed to quantitatively investigate the influence of carbon content in solidifying steel on shell growth.

Anomaly in the unevenness of shell thickness and the depth of ripple mark was revealed for an ultra-low carbon steel and a hypo-peritectic carbon steel. Increase of the superheat in molten steel can reduce the depth of ripple mark.

Furthermore, analysis of solidification of $\mathrm{Fe}-\mathrm{C}$ alloys accompanying with $\delta / \gamma$ transformation was made to clarify the shell deformation resulting in the anomaly in surface roughness and shell thickness unevenness of solidifying shells for the ultra-low carbon steel and the hypo-peritectic carbon steel.

The carbon content dependence of the calculated stress index is in good agreement with the observed one of the uneven shell growth. The product between the volume and the rate of the solidification shrinkage and the $\delta / \gamma$ transformation formed until crystallization is completed after a shell begins to have a strength and, i.e., during a fraction sold of 0.7 to 1.0 , exhibits two peaks for the ultra-low carbon steel and the hypo-peritectic carbon steel. Besides the analysis shows that a mild cooling in a mold can reduce the stress generation.

\section{REFERENCES}

1) A. Grill and K. Brimacombe: Ironmak. Steel. 3 (1976) 76-79.

2) S. N. Singh and K. E. Blazek: Open Hearth Proc. AIME 59 (1976) 264 283.

3) T. Saeki, S. Oguchi, S. Mizoguchi, T. Yamamoto, H. Misumi and S. Tuneoka: Tetsu-to-Hagané 68 (1982) 1773-1781.

4) T. Matsumiya, T. Saeki, J. Tanaka and T. Ariyoshi: Tetsu-to-Hagané 68 (1982) 1782-1791.

5) T. Mizoguchi, S. Ogibayashi and T. Kajitani: Tetsu-to-Hagané 81 (1995) 971-976.

6) H. Mizukami, S. Hiraki, M. Kawamoto and T. Watanabe: ISIJ Int. 39 (1999) 1262-1269.

7) H. Esaka, T. Shirakami, T. Mizoguchi and S. Ogibayashi: Tetsu-toHagané 81 (1995) 631-636.

8) T. Kajitani, H. Esaka, M. Wakoh, H. Misumi and S. Ogibayashi: Tetsuto-Hagané 81 (1995) 1055-1060.

9) H. Tonomo, W. Kurz and W. Heinemann: Metall. Trans. 12B (1981) 409-411.

10) M. Kudoh, T. Takahashi and Y. Deguchi: Tetsu-to-Hagané 73 (1987) S901.

11) S. Dong, E. Niyama and K. Anzai: ISIJ Int. 35 (1995) 730-736.

12) D. P. Poirier and G. H. Geiger: Transport Phenomena in Metallurgy, (TMS, 1994), 337.

13) T. Nishi, H. Shibata, K. Tsutsumi, H. Ohta and Y. Waseda: ISIJ Int. 42 (2002) 498-503.

14) J. J. Berkerman: Physical Surfaces, (Academic Press, London,1970) p. 12.

15) Handbook of Physical Properties of Molten Steels and Molten Fluxes, (ISIJ, 1972) p. 124.

16) Handbook of Physical Properties of Molten Steels and Molten Fluxes, (ISIJ, 1972) p. 128.

17) Y. Ueshima, S. Mizoguchi, T. Matsumiya and H. Kajioka: Metall Trans. 17B (1986) 845-859.

18) K. Shin, T. Kajitani, T. Suzuki and T. Umeda: Tesu-to Hagané 78 (1992) 587-593.

19) Kikaikogaku-Binran (Handbook of Mechanical Engineering in Japanese), (Nippon Kikai Gakkai, 1987) p. A4-12. 